\title{
Tato Arts Center in Badung, Bali
}

\author{
Made Bagus Angga Maheswara ${ }^{1}$, Tri Anggraini Prajnawrdhi ${ }^{2}$, I Wayan Wiryawan ${ }^{3}$
}

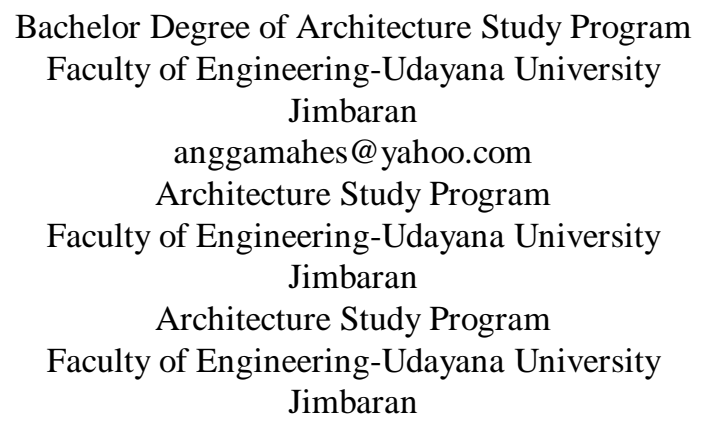

\begin{abstract}
The centre of arts was a place for activity that related to the arts itself, as a place to show the local art and culture, and provide us information about the artworks that made by the artist and show it to the visitors or consumers by displaying these artworks into art exhibition that expected to be able reach a wider market. This art centre published as a gallery that will accommodate tattoo artist to show their artwork as a paintings and tattoos on synthetic leather. The research of this study using qualitative method by spreading questionnaires, studying literature with local regulations including the application of the characteristics of traditional Balinese architecture that are harmoniously environmentally friendly, and field observation techniques on objects related to facilities found in art centers such as galleries, exhibitions and tattoo studios where the results of the research steps are the results of questionnaires with 70 respondents $98,6 \%$ were in-terested in tattoo art and agreed to realize the planning of the Tattoo Art Center in Badung, The result of this literature study and observation were the architecture that used generally between Balinese architecture with modern architec-ture in the building that used neo vernacular concept. This building was applying the neo vernacular concept in the gallery section where the gallery facade applies the Tri Angga concept, such as the head, body and legs which were in traditional forms, using pyramid roofs which have mudras and participate in Ciledu and used local materials in the form of bricks and natural stones through application it produced concept of neo vernacular.
\end{abstract}

Index Terms - neo vernacular, art center, tattoo, gallery, facade.

\section{INTRODUCTION}

Tattoo art center is a facility and forum for artists, especially tattoo artists in Bali, this art center has a retail tattoo art gallery and a history of tattoo development, exhibiting the work of tattoo artists, in addition there is a workshop for tourists, visitors and others. The tattoo art center is expected to function as a means of introducing tattoo art to the wider community, utaman-ya as a place to exhibit, workshops and sell tattoo art work, in addition to being able to change the identity of tattoos in the community and bridge between tattoo artists and enthusiasts tattoo art. The background to the use of the neo vernacular concept in this art center is because tattoo art is very closely related to culture and this neo vernacular concept implements cultural elements such as layout, elements and materials with the purpose of being able to introduce the art of tattooing, this art center can maintain traditional Balinese architecture .

The development of tattoos in Bali, although not fast, but tattoo users in Bali are increasingly in demand. 
Although there is no statistically significant calculation of the number of tattoo users in Bali, this can be seen with the rise of tattoo studios in Bali that offer tattooing services. According to Lionk (2018) the number of tattoo studios in Bali is approximately 92 tattoo studios spread across Badung Regency and Denpasar City with an average of 2530 people per month per tattoo studio. This proves that the interest of tattoo art in Bali is relatively high.

The presence of the Tattoo Arts Center in Badung is expected to be able to answer the problem of the absence of a special forum to display the potential of tattoo artists in Bali. One of the facilities contained in the Art Center is a gallery. The gallery is important because it is a place for tattoo artists to introduce their work to the wider community. In this journal, the discussion will be devoted to the scope of the gallery facade at the Art Center where the facade is important in fostering the attention of visitors. The concept of the facade that is applied must of course also be able to represent the function of the building itself which in this case is to accommodate works of art created by tattoo artists. Thus, the concept in the gallery facade refers to the neo-vernacular concept that emphasizes local culture and harmony between buildings, nature and the environment.

\section{RESUlt AND ANALISYS}

\section{A. Neo-Vernacular}

Neo Vernacular Architecture is an understanding of the flow of Post-Modern Architecture which was born as a response and criticism of modernism that prioritizes the value of rationalism and functionalism that are influenced by the development of industrial technology. NeoVernacular architecture is an architecture whose concept in principle considers the rules, normative, cosmological, the role of local culture in people's lives and the harmony between buildings, nature, and the environment.

Neo-Vernacular architecture, not only applies physical elements that are applied in modern forms but also nonphysical elements such as culture, thought patterns, beliefs, layout, religion and others.

Building is an art culture that consists in repetition of a limited number of types and in its adaptation to local climate, materials and customs.

According to Jencks [1] Neo Vernacular architectural features use a bumbungan roof covering the level of the wall to almost the ground so that more roofs are likened to the elements of the covering and greeting than the walls depicted as defense elements, buildings dominated by bricks, returning the shape traditional forms that are environmentally friendly with more vertical proportions, unity between open interiors through modern elements with open spaces outside buildings, and strong colors (see figure 1).

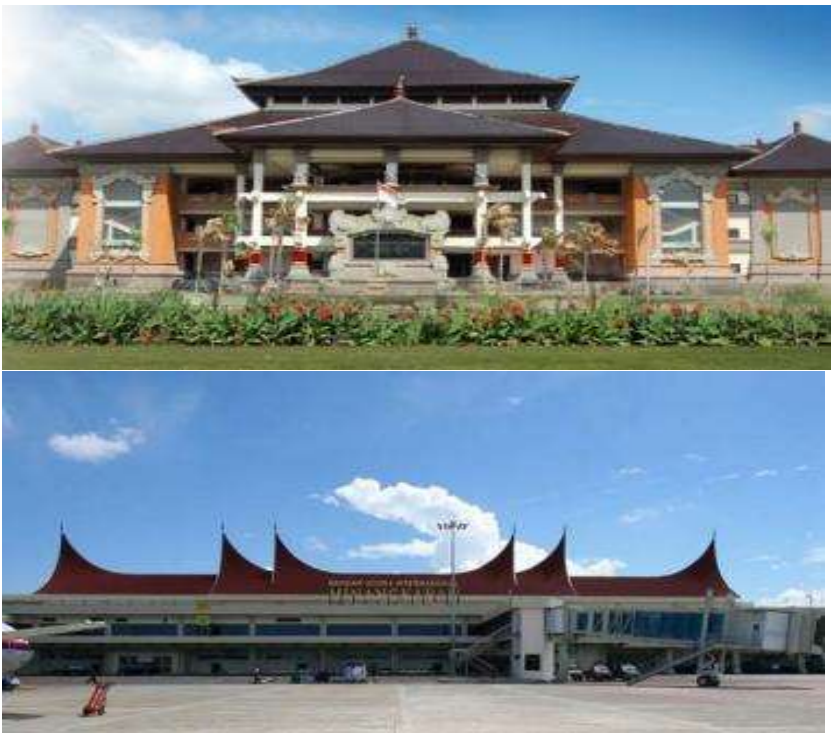

Fig. 1. Office and Airports

\section{B. Design of Pattern, Orientation and Form of Mass Building Patterns}

The appearance of a building, especially its shape and facade, is not created without any underlying process. In site design, linear zoning of the site is the first factor that determines the pattern creation and orientation to the shape of the building mass where the linear zoning of the site at the Art Center is determined at the position of the main road to the west of the site so that the linear zoning is successively from the west the site is a public zone, a semipublic zone, and a private zone. After zoning, the circulation in the site is divided into two, namely the circulation of visitors and managers determined from the location of the entrance which is in the front, the public zone. The location of the entrance itself is adjusted to the closest access to the manager's circulation to the private zone from the west side of the site (see figure 2).

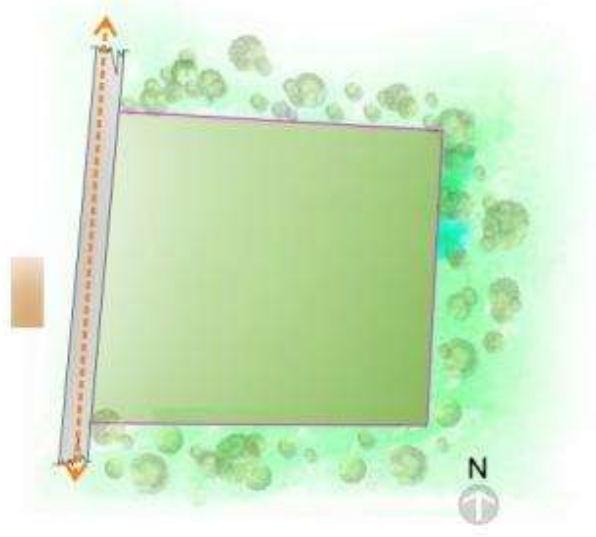



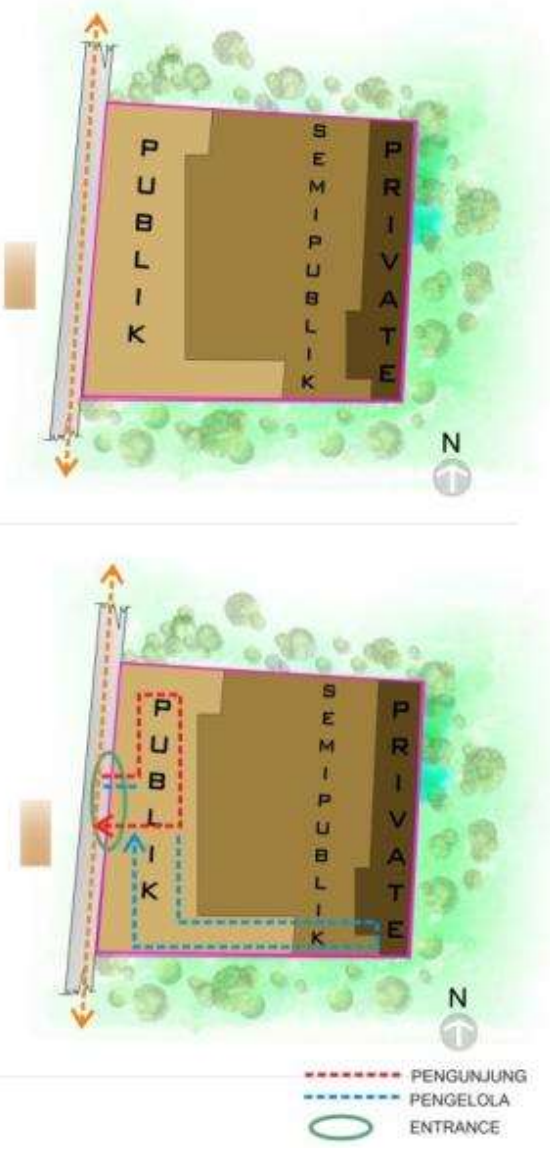

Fig. 2. Zoning and Circulation Design Process on the Site as Determinants of the Pattern, Orientation, and Mass Form of the Art Center

Based on zoning and circulation, laying and building mass patterns are obtained that are adjusted to the zone characteristics of each facility contained in the art center. The laying and patterning of the masses is adjusted to the outdoor gallery which is the center of orientation so that the mass patterns of the buildings surrounding the outdoor gallery can make the mass patterns in the arts center more dynamic and give a more aesthetic and monotonous impression. In developing this mass pattern, there is a process of adjusting to the shape of the square in which the orientation pattern is created dynamically so that it can add to the aesthetics of the site (see Figure 3).

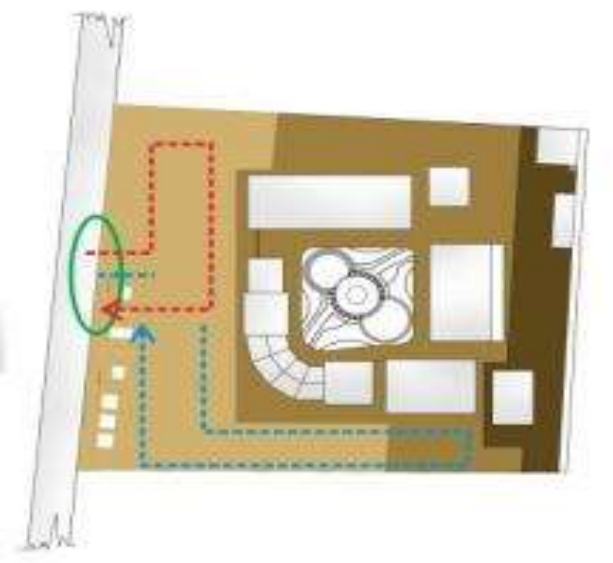

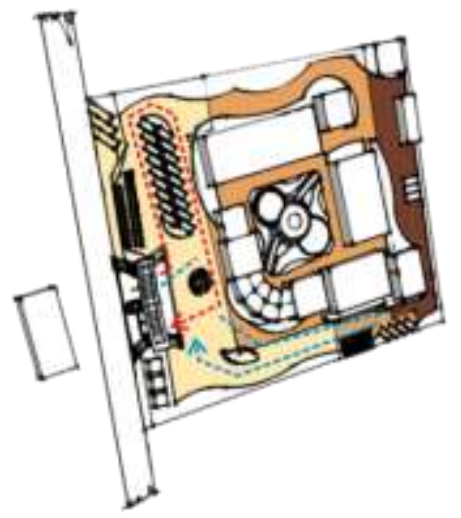

Fig. 3. Pattern Design Process, Orientation, and Mass Form of Art Center

From the above process, both zoning to the development of patterns, orientations, and forms of mass were found that the appropriate form of mass for the gallery is the beam. While the lobby, artshop and café which were previously also rectangular in shape were transformed into radials due to adjustments to the outdoor gallery (see figure 4).
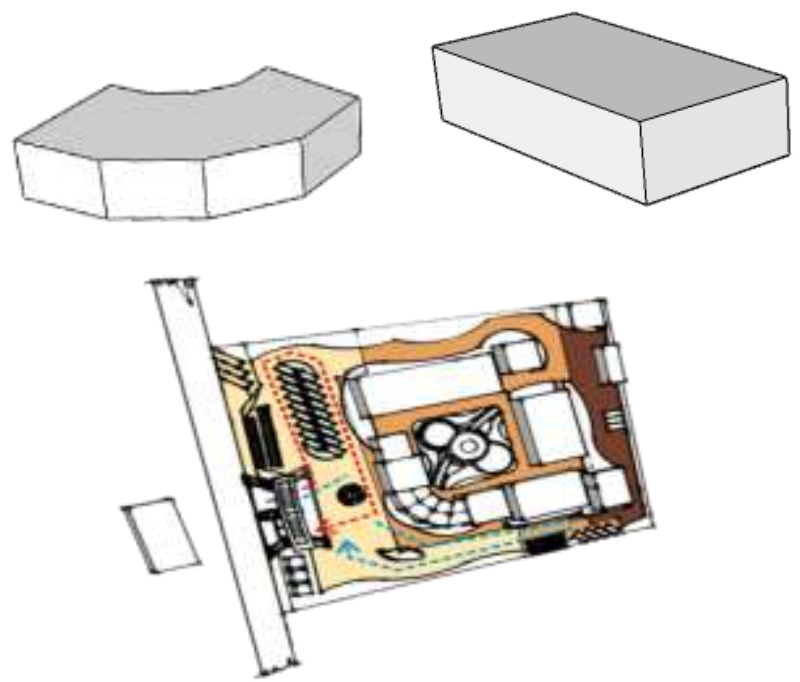

Fig. 4. Output Mass Forms of Lobby, Artshop and Cafe Galleries

\section{Design of Pattern, Orientation and Form of Mass Building Patterns}

In the design there are several processes that affect the pattern, orientation, and shape of the building mass from site design to the design of the building itself, in which efforts are made to display the neo vernacular impression. The application of the neo-vernacular concept to the gallery's facade display is demonstrated by several stages of transformation from adjusting the shape of the roof, to the shape of the wall, to the material to be used as in the gallery. limasan roof was chosen to be easily recognized and gave the impression of Balinese architecture, then on the limasan roof there was a mudra decoration, and joined ciledu. The structure on the roof uses a wide-flange steel roof structure. (see picture 5). 

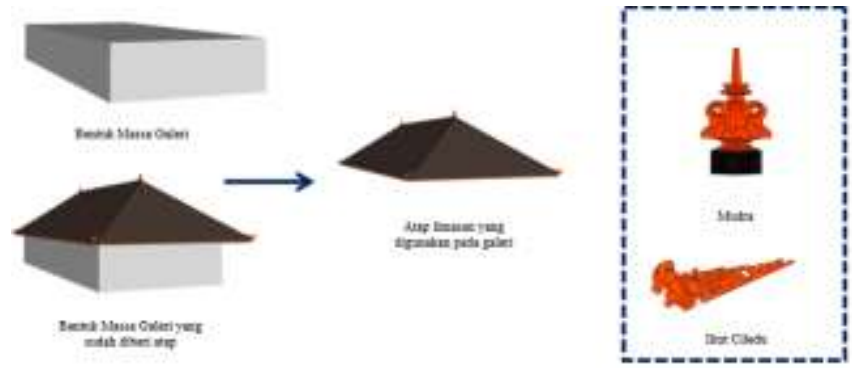

Fig. 5. The shape of the Gallery Mass and the Gallery Roof Display

Of course the appearance of the gallery's facade must also refer to the principle of Neo Vernacular Architecture which restores traditional forms, so the gallery facade uses the tri angga concept where there is a head (main), a body (middle) and legs. (nista) which has the largest spatial value meaning-Using gray (on walls), black (on steel construction), and brown (on wood construction). The finishing materials used also combine a combination of brick and natural stone which is a local material with cement plaster that is left to its original color. The choice of colors and materials is certainly not unlucky, besides adjusting to the neo vernacular principles to make it look aesthetically also consider several factors such as function, safety, durability, suitability and strength of the material to be more efficient. (see figure 6).
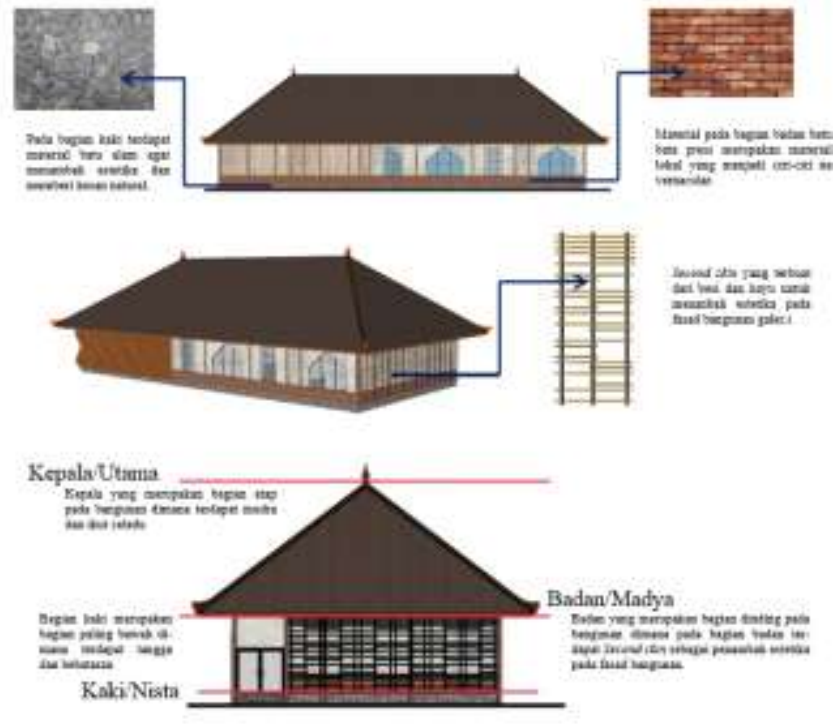

Fig. 6. Application of materials and colors that fit the Neo Ver-nakular concept

Next (Figure 7) is the main gallery facade view from the perspective of the bird's eye and normal eye where it can be seen in the perspective image displaying the concept of the triang there are the head, body and legs. On the facade the head part applies a limasan roof where there is mudra and follows ciledu as a traditional Balinese element, the body part applies local materials such as bricks and natural stone. Second skin as an aesthetic enhancer on the building facade on the foot, there is a platform like a ladder which is a rule of architecture neo vernacular.

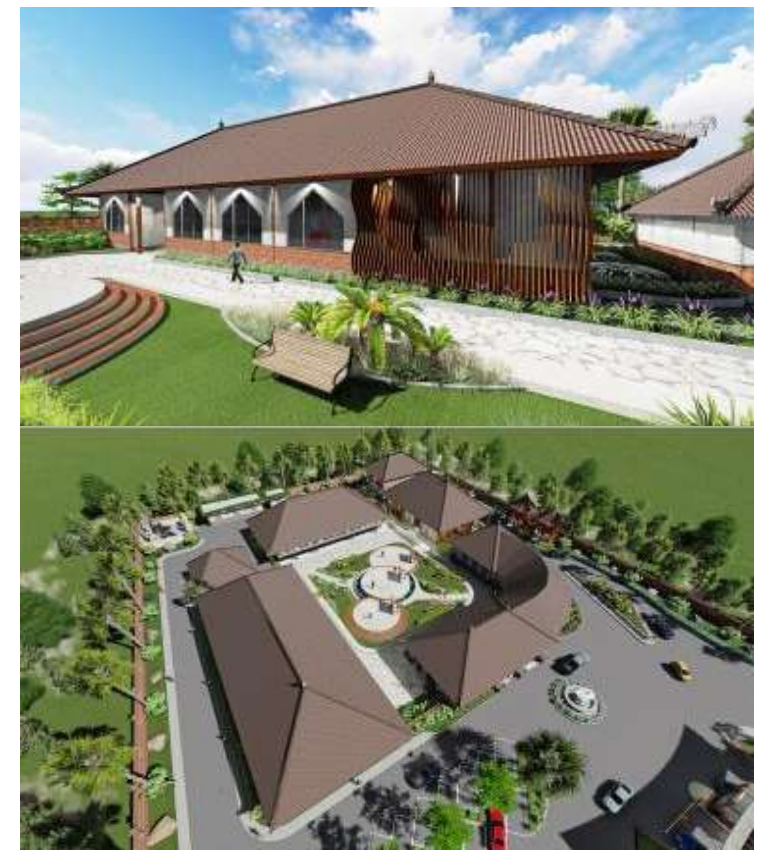

Fig. 7. Gallery, Normal Eye Perspective (left), and Bird Eye (right)

\section{CONCLUSION}

In the above explanation, the design of the Tattoo Art Center in Badung will be a new facility to introduce tattoo art and remove the bad stigma of tattoo art in the community in order to raise the potential of tattoo art. Of course, in the process of designing this facility there are challenges on how to display neo vernacular figures in buildings so that visitors can inform the function inside. Therefore, there are a number of site design and building design explorations to address these challenges to find an appropriate display of the building facade, especially the gallery which is one of the main functions of this facility. Not just a patch to add aesthetic value but also functional. So after assessing the appearance of the facade in advance, visitors are expected to be moved to enter the gallery and enjoy the process of appreciation for the tattoo works exhibited by artists.

The advice that can be given related to planning the appearance of the facade is not wrong if you dare to explore the materials used on the exterior and preserve culture to support the appearance of the building. However, it is also a good idea to consider the cost factors, the suitability of construction and local environmental weather conditions because these three things become a challenge in designing the exterior appearance of the building.

\section{REFERENCES}

[1] Jecks, Charles., "The New Pradigm in Architecture", London : Yale University Press, 2002. 